\title{
Evaluation of suprascapular nerve neurotization after nerve grafting or transfer in the treatment of brachial plexus traction lesions
}

\author{
Martijn J. A. Malessy, M.D., Ph.D., Godard C. W. de Ruiter, M.D., \\ Kees S. De Boer, M.D., AND RalPh T. W. M. Thomeer, M.D., Ph.D. \\ Departments of Neurosurgery and Rehabilitation Medicine, Leiden University Medical Center, \\ Leiden, The Netherlands
}

\begin{abstract}
Object. The aim of this retrospective study was to evaluate the restoration of shoulder function by means of suprascapular nerve neurotization in adult patients with proximal C-5 and C-6 lesions due to a severe brachial plexus traction injury (BPTI). The primary goal of brachial plexus reconstructive surgery was to restore the biceps muscle function and, secondarily, to reanimate shoulder function.

Methods. Suprascapular nerve neurotization was performed by grafting the C-5 nerve in 24 patients and by accessory or hypoglossal nerve transfer in 29 patients. Additional neurotization involving the axillary nerve could be performed in 18 patients.

Postoperative needle electromyography studies of the supraspinatus, infraspinatus, and deltoid muscles showed signs of reinnervation in most patients; however, active glenohumeral shoulder function recovery was poor. In nine (17\%) of 53 patients supraspinatus muscle strength was Medical Research Council (MRC) Grade 3 or 4 and in four $(8 \%)$ infraspinatus muscle power was Grade 3 or 4 . In 18 patients in whom deltoid muscle reinnervation was attempted, MRC Grade 3 or 4 function was demonstrated in two (11\%). In the overall group, eight patients (15\%) exhibited glenohumeral abduction with a mean of $44 \pm 17^{\circ}$ (standard deviation [SD]) (median $45^{\circ}$ ) and four patients $(8 \%$ ) exhibited glenohumeral exorotation with a mean of $48 \pm 24^{\circ}(\mathrm{SD})$ (median $\left.53^{\circ}\right)$. In only three patients $(6 \%)$ were both functions regained.

Conclusions. The reanimation of shoulder function in patients with proximal C-5 and C-6 BPTIs following suprascapular nerve neurotization is disappointingly low.
\end{abstract}

\section{KEY WORDS • brachial plexus injury - grafting - nerve transfer • suprascapular nerve $\bullet$ shoulder function}

Severe brachial plexus traction lesions in adults frequently present with rupture or avulsion of spinal C-5 and C-6 nerves, which results in the loss of active glenohumeral abduction, exorotation, and elbow flexion. The C-7, C-8, and T-1 spinal nerves may be involved as well, affecting the function of the lower arm and hand. It is generally agreed that the primary goal of nerve repair in cases involving these lesion types is restoration of biceps muscle function. The reanimation of shoulder function is the second goal. ${ }^{14,24}$ In adults who have undergone brachial plexus reconstruction, good results of shoulder function recovery have been reported. $1,4,7,10,21,22,24,28,34,35$ Interpretation of the data presented, however, is difficult for the following reasons. First, the outcome data pertaining to different types and localizations of lesions have been pooled - for instance, superior trunk lesions have been grouped with

Abbreviations used in this paper: $\mathrm{BPTI}=$ brachial plexus traction injury; $\mathrm{EMG}=$ electromyography; $\mathrm{ES}$ = electrical stimulation; MRC = Medical Research Council; $\mathrm{ROM}=$ range of motion; $\mathrm{SD}=$ standard deviation. axillary nerve lesions, and traction lesions with gunshot wounds and sharp wounds. Second, results of multiple nerve repair techniques for shoulder function reanimation have been pooled, such as those of various grafting procedures with transfers and those of neurolysis or end-to-end repair with grafting. Third, the results of nerve repair are sometimes combined with those of secondary surgery without specifying the contribution of the constituting parts. Furthermore, the severity of the lesions found intraoperatively has not been specified in detail: information on histology of nerve stumps is not provided and the length of the grafts is not specified. Finally, the analysis and scoring methods applied to assess postoperative shoulder function are generally not clearly outlined. For these reasons, it remains unclear which degree of shoulder function recovery can be attributed to a particular repair technique.

In the present study, we evaluated the restoration of shoulder function in patients who underwent suprascapular nerve neurotization in a selected group of 53 patients with a severe proximal BPTI in whom a superior trunk 
repair was not possible. Restoration of shoulder function was the second goal of surgery; priority was given to elbow flexion reanimation. Suprascapular nerve neurotization was performed by C-5 grafting and as well as accessory or hypoglossal nerve transfer. Functional outcome was analyzed to determine specific factors affecting functional recovery.

\section{CLINICAL MATERIAL AND METHODS Patient Population}

One hundred fifty-five adults with severe BPTIs were surgically treated at the department of neurosurgery of the Leiden University Medical Center. Intraplexal nerve grafting and/or extra/intraplexal nerve transfer was performed. The primary goal was to restore active elbow flexion and, secondarily, to reanimate active glenohumeral function.

In this retrospective study inclusion criteria included the following. 1) There should be an intra- or juxtaforaminal rupture or avulsion from C-5 and C-6. 2) The proximal stump in nerve grafting for shoulder function reanimation was the C-5 spinal nerve. 3) The distal stump of nerve repair was the suprascapular nerve or both the suprascapular nerve and axillary nerve (consequently, patients with a neurotmetic lesion limited to the posterior division of the superior trunk, or of the axillary nerve and/or suprascapular nerve as part of a more extended brachial plexus lesion were not included). 4) Each distal stump was connected to only one proximal donor stumpcombination of two donors to one distal stump hampers the assessment of the contribution of each individual donor stump to the result. 5) Extraplexal-intraplexal nerve transfers were conducted when the C-5 outlet was not available or suited for grafting to reanimate shoulder muscles. 6) The postoperative follow-up period was at least 2 years.

Also excluded were patients with an apparent axonotmetic lesion of the suprascapular nerve or axillary nerve. The contribution to functional recovery from grafting or transfer to the suprascapular nerve is difficult to determine when some degree of spontaneous recovery in the axonotmetic axillary nerve has occurred. Fifty-three patients (47 men, six women) met these criteria and constitute the basis of the present study (Tables 1-4). The majority of patients had sustained their injuries in traffic accidents. Clinically, all patients exhibited normal function of anterior serratus, rhomboid, and trapezius muscles. Before surgery, all patients underwent needle EMG examination to document the complete absence of activity at a maximum voluntary effort. This investigation included the trapezius muscle to exclude an accessory nerve lesion. A computerized tomography myelography study was obtained prior to surgery to detect root avulsions. Including the information pertaining the surgical exposure, all patients were shown to have intra- or juxtaforaminal nerve rupture or root avulsion of C-5 and C-6 as well as extensive neuroma formation and scarring of the superior trunk, including the proximal part of its divisions. In some patients, avulsion of the C7-T1 roots had also occurred. Plain radiography revealed scapular fractures in nine patients $(17 \%)$ and humeral fractures in nine patients (17\%), one of whom had sustained a combination of both fractures. The mean age of the patients at surgery was $24.6 \pm 8.4$ years $(\mathrm{SD})$ (median 23.3 years). The mean interval between trauma and operation was $128.6 \pm 71.4$ days $(\mathrm{SD})$ (median 117 days). The mean follow-up period was $3.3 \pm 1.7$ years (SD) (median 3 years). At 6-month intervals, the force exerted by the deltoid, supraspinatus, infraspinatus and biceps muscles was assessed according to the MRC scale. ${ }^{31}$ In evaluating the active elbow flexion, the function of the brachioradial muscle and a possible so-called Steindler effect from lower-arm muscles were taken into account. Repeated postoperative needle EMG studies of the target muscles were performed in all patients. Reinnervation was documented by the activity pattern at maximal voluntary effort.

\section{Examination of Shoulder Function}

The shoulder function evaluation was adapted from that reported by Narakas $^{23}$ and applied as follows. First, the passive ROM of abduction, exorotation in adduction, and exorotation in maximal abduction was examined, focusing on the presence of contractures. Second, the active range of abduction and exorotation was analyzed and divided in two distinct parts: namely, true glenohumeral motion and the total ROM, which combines the glenohumeral excursion and thoracoscapular rotations. True glenohumeral abduction occurs in the frontal plane and was defined as the angle " $\alpha$ " formed by the position of the humerus and the medial scapular margin at maximal abduction. Thoracoscapular rotation was defined as the angle " $\beta$ " formed by the position of the medial scapular margin at rest and at maximal abduction. This was measured by simultaneous palpation of the upper part of the extended arm with one hand and the inferior angle of the scapula with the other during an attempt of maximal abduction. The total functional abduction range " $\partial$ " is defined as the sum of $\alpha$ and $\beta$ (Fig. 1). The patient was asked to stand straight - thus, lateroflexion and extension of the spine (Fig. 2) was not appreciated by the examiner, and neither was glenohumeral elevation resulting from pectoralis major activity. To examine whether the force was sufficient to abduct against gravity (MRC Grade 3), the patient was asked to tilt the spine to the contralateral side while keeping the arm maximally abducted. The glenohumeral abduction in the acquired ROM could only be effected by contraction of the supraspinatus and/or deltoid muscle reinnervated as a result of grafting or transfer.

True glenohumeral exorotation is defined as the angle between the position of the $90^{\circ}$ (actively or passively) flexed elbow resting against the belly and the position of the flexed elbow after exorotation with the upper arm in adduction until the scapula starts rotating (Fig. 3). During the examination of the exorotation the patient was asked to stand straight as well. The exorotation measured could only be effected by the reinnervated infraspinatus or teres minor muscles. The total functional range is defined as the sum of both the thoracoscapular rotation and the glenohumeral excursion. None of the patients exhibited joint contractures that limited the active ROM.

\section{Surgical Technique}

Grafting. The surgical technique was similar to that previously described..$^{20}$ The entire trajectory of the brachial plexus was exposed. Root avulsions were confirmed 


\section{Suprascapular nerve neurotization in brachial plexus lesions}

TABLE 1

Grafting of the $C-5$ nerve to the suprascapular nerve in 11 patients*

\begin{tabular}{|c|c|c|c|c|c|c|c|c|c|c|c|}
\hline $\begin{array}{l}\text { Case } \\
\text { No. }\end{array}$ & Diagnosis & Additional Nerve Repair & $\begin{array}{l}\text { Age } \\
\text { (yrs) }\end{array}$ & $\begin{array}{l}\text { Trauma-Op } \\
\text { Interval } \\
\text { (days) }\end{array}$ & $\begin{array}{l}\text { Graft } \\
\text { Length } \\
(\mathrm{cm})\end{array}$ & \multicolumn{3}{|c|}{$\%$ of Myelin } & \multicolumn{3}{|c|}{ MRC Grade } \\
\hline 1 & N C-5, AV C6-T1 & $\begin{array}{l}\text { C4-rad lat med, } \\
\text { 3rd-5th ICNs-MC }\end{array}$ & 18 & 30 & 7 & $25-50$ & & & 0 & 0 & 4 \\
\hline 2 & $\begin{array}{l}\text { partial C-5 AV, } \\
\text { C6-T1 AV, AXN N }\end{array}$ & $\begin{array}{l}\text { XII-MC, XII-distal XII, } \\
\text { C4-rad lat med }\end{array}$ & 17 & 67 & 6 & $50-75$ & & & $3 \dagger$ & 1 & 3 \\
\hline 3 & TS N, TM, TI & C6-ADTS, C7-C7 & 24 & 134 & 3.5 & $>75$ & $>75$ & $\mathrm{C}-5<\mathrm{C}-6$ & 0 & 1 & 3 \\
\hline 5 & TS N, TM N & C6-LC & 18 & 194 & 8 & & & & 1 & 0 & 3 \\
\hline $6 \ddagger$ & C-5 N, C-6 AV & C5-MC & 23 & 281 & 4 & $>75$ & & & 1 & 1 & 3 \\
\hline $7 \ddagger$ & TS N, C7-T1 AV & $\begin{array}{l}\text { C5-LC, C6-(LC, } \\
\text { rad med med), } \\
\text { 4th/5th ICNs-pec }\end{array}$ & 22 & 36 & 2 & $<25$ & $25-50$ & $\mathrm{C}-5<\mathrm{C}-6$ & 0 & 0 & 4 \\
\hline $8 \ddagger$ & $\begin{array}{l}\text { C-5, C-6 N, } \\
\text { C7-T1 AV }\end{array}$ & $\begin{array}{l}\text { C5-MC, C-6-rad } \\
\text { med med, ICN-pec }\end{array}$ & 41 & 145 & 4 & $50-75$ & $50-75$ & $C-5=C-6$ & 0 & 0 & 0 \\
\hline
\end{tabular}

$*$ ADTS = anterior division of the superior trunk; AV = avulsion; AX = axonotmesis; ICN = intercostal nerve; infra = infraspinatus muscle; intrafor = intraforaminal; $\mathrm{LC}=$ lateral cord $\mathrm{MC}=$ musculocutaneous nerve; $\mathrm{N}=$ neurotmesis; pec $=$ pectoral nerve; rad lat med = lateral root of the median nerve; rad med med $=$ medial root of the median nerve; supra = supraspinatus muscle; $\mathrm{TI}=$ inferior trunk; $\mathrm{TM}=$ medial trunk; $\mathrm{TS}=$ superior trunk; $\mathrm{XII}=$ hypoglossal nerve.

$\dagger$ Glenohumeral abduction $20^{\circ}$, total abduction $45^{\circ}$

$\ddagger$ Grafting to both suprascapular nerve and musculocutaneous nerve (or lateral cord or anterior division of the superior trunk).

TABLE 2

Grafting of the C-5 nerve to the suprascapular and axillary nerves in 13 patients

\begin{tabular}{|c|c|c|c|c|c|c|c|c|c|c|c|c|c|}
\hline $\begin{array}{l}\text { Case } \\
\text { No. }\end{array}$ & Diagnosis & Additional Nerve Repair & $\begin{array}{l}\text { Age } \\
\text { (yrs) }\end{array}$ & $\begin{array}{l}\text { Trauma-Op } \\
\text { Interval } \\
\text { (days) }\end{array}$ & \multicolumn{2}{|c|}{ Graft Length $(\mathrm{cm})$} & \multicolumn{3}{|c|}{$\%$ of Myelin } & \multicolumn{4}{|c|}{ MRC Grade } \\
\hline 1 & $\begin{array}{l}\mathrm{C}-5, \mathrm{C}-6 \mathrm{~N} \\
\mathrm{C} 7-\mathrm{T} 1 \mathrm{AV}\end{array}$ & $\begin{array}{l}\text { C6-LC, } \\
\text { ICN-rad med med }\end{array}$ & 32 & 60 & 7 & 7 & $50-75$ & $50-75$ & $\mathrm{C}-5<\mathrm{C}-6$ & 2 & 0 & 2 & 5 \\
\hline 2 & $\begin{array}{l}\mathrm{C}-5 \mathrm{~N}, \\
\mathrm{C} 6-\mathrm{C} 7 \mathrm{AV}\end{array}$ & 3rd-6th ICN-MC & 23 & 67 & 8 & 8 & $25-50$ & & & 0 & 0 & 0 & 2 \\
\hline 3 & $\begin{array}{l}\mathrm{C}-5, \mathrm{C}-6 \mathrm{~N}, \\
\text { partial } \\
\mathrm{C} 7-\mathrm{C} 8 \mathrm{AV}\end{array}$ & C6-MC & 16 & 108 & 6 & 13 & $50-75$ & $50-75$ & $C-5=C-6$ & $3 *$ & $3 *$ & $3 *$ & 5 \\
\hline 4 & TS, TM N & C6-LC, TM-rad & 38 & 367 & 4 & $8.5(2)$ & $50-75$ & $>75$ & $C-5=C-6$ & 0 & 0 & 0 & 2 \\
\hline 5 & $\begin{array}{l}\mathrm{C}-5, \mathrm{C}-6 \mathrm{~N}, \\
\mathrm{C} 7-\mathrm{T} 1 \mathrm{AV}\end{array}$ & $\begin{array}{l}\text { C6-LC, } \\
\text { 5th/6th ICN-pec }\end{array}$ & 26 & 117 & & & $>75$ & $<25$ & $C-5>C-6$ & 0 & 0 & 0 & 0 \\
\hline 6 & $\begin{array}{l}\mathrm{C}-5, \mathrm{C}-6 \mathrm{~N} \\
\mathrm{C} 7-\mathrm{T} 1 \mathrm{AV}\end{array}$ & $\begin{array}{l}\text { C6-MC, } \\
\text { 2nd-4th ICN-rad } \\
\text { lat med }\end{array}$ & 20 & 129 & 5 & $10(2)$ & $25-50$ & $25-50$ & $C-5=C-6$ & 0 & 0 & 2 & 0 \\
\hline 7 & TS N & C6-MC & 41 & 109 & 8.5 & $7.5(3)$ & $25-50$ & $25-50$ & $C-5=C-6$ & 0 & 0 & 1 & 3 \\
\hline 11 & $\begin{array}{l}\mathrm{C}-5, \mathrm{C}-6 \mathrm{~N} \\
\mathrm{C} 7-\mathrm{T} 1 \mathrm{AV}\end{array}$ & $\begin{array}{l}\text { 4th-6th ICN-MC, } \\
\text { 3rd ICN-pec, } \\
\text { C4-rad lat med }\end{array}$ & 17 & 146 & 6 & $11(2)$ & $>75$ & & & 1 & 0 & 1 & 4 \\
\hline 12 & $\begin{array}{l}\text { C-5, C-6 N, } \\
\text { C-7 AV, C-8, } \\
\text { T-1 AX/N }\end{array}$ & C6-MC & 27 & 159 & 8.5 & $11(2)$ & $>75$ & $>75$ & $C-5=C-6$ & 0 & 0 & 0 & 0 \\
\hline 13 & $\begin{array}{l}\text { C-5, C-6, } \\
\text { TM, TI N }\end{array}$ & $\begin{array}{l}\text { C6-LC, C7-rad, } \\
\text { TI-FM }\end{array}$ & 17 & 77 & 9 & 11 & $<25$ & $50-75$ & C-5 $<$ C- 6 & 0 & 0 & 0 & 4 \\
\hline
\end{tabular}

* Glenohumeral abduction/exorotation 45 and $15^{\circ}$, respectively.

$\dagger$ Glenohumeral abduction $80^{\circ}$. 
M. J. A. Malessy, et al.

TABLE 3

Accessory to suprascapular nerve transfer in 21 patients*

\begin{tabular}{|c|c|c|c|c|c|c|c|c|}
\hline $\begin{array}{l}\text { Case } \\
\text { No. }\end{array}$ & Diagnosis & Additional Nerve Repair & $\begin{array}{l}\text { Age } \\
\text { (yrs) }\end{array}$ & $\begin{array}{c}\text { Trauma-Op } \\
\text { Interval } \\
\text { (days) }\end{array}$ & $\begin{array}{c}\text { Graft } \\
\text { Length } \\
(\mathrm{cm})\end{array}$ & \multicolumn{3}{|c|}{ MRC Grade } \\
\hline 1 & $\begin{array}{l}\mathrm{C}-5 \mathrm{~N}, \mathrm{C}-6 \mathrm{AV} \\
\mathrm{C}-7 / \mathrm{C}-8 \text { partial AV }\end{array}$ & C5-LC, 5th/6th ICN-pec med & 26 & 131 & & 2 & 0 & 4 \\
\hline 2 & C-5 AV, C-6 partial AV & & 25 & 282 & & $3 \dagger$ & 0 & 5 \\
\hline 3 & C-5 N, C6-T1 AV & C5-LC & 28 & 84 & 6 & 0 & 0 & 2 \\
\hline 4 & $\begin{array}{l}\text { C-5/C-6 intrafor N, } \\
\text { C-7/C-8 AV, T1 partial AV }\end{array}$ & 4th-6th ICN-MC & 16 & 148 & & 0 & 0 & 2 \\
\hline 6 & C-5 N, C6-T1 AV & $\begin{array}{l}\text { C5-MC, C4-rad lat med, } \\
\text { 3rd/4th ICN-pec med }\end{array}$ & 16 & 20 & & $3 \dagger$ & 0 & 5 \\
\hline 7 & C-5 N, C6-T1 AV & C4-med, C5-MC, IC-pec & 28 & 59 & & 0 & 0 & 3 \\
\hline 8 & C-5-T1 AV & 4th-6th ICN-MC, 3rd ICN-pec med & 23 & 75 & & 1 & 1 & 2 \\
\hline 9 & C-5 intrafor N, C-6 AV & 4th-6th ICN-MC & 34 & 179 & & 0 & 0 & 3 \\
\hline 10 & C5-C7 AV & 3rd-5th ICN-MC & 25 & 200 & & 0 & 0 & 2 \\
\hline 15 & C-5/C-6 AV, C-7 partial AV & 3 rd-5th ICN-MC & 17 & 89 & & 0 & 0 & 4 \\
\hline 16 & C-5/C-6 AV, C-7 AX & & 17 & 82 & & $4 \dagger$ & $4 \ddagger$ & 4 \\
\hline 17 & C5-7 AV & 3rd-5th ICN-MC & 39 & 167 & & 0 & 1 & 3 \\
\hline 18 & C-5 N, C-6/C-7 AV & $\mathrm{C} 5-\mathrm{MC}$ & 16 & 62 & 3 & 1 & 1 & 4 \\
\hline 19 & C-5 N, C6-T1 AV & $\begin{array}{l}\text { C5-(MC, rad lat med), } \\
\text { 3rd-5th ICN-MC }\end{array}$ & 21 & 201 & 6 & 0 & 0 & 4 \\
\hline 20 & C-5/C-6 AV & 3rd-5th ICN-MC & 38 & 203 & 4 & 0 & 0 & 1 \\
\hline 21 & C-5/C-6/C-7 AV, C-8/T1 AX & 3rd-5th ICN-MC & 23 & 117 & & 0 & 0 & 0 \\
\hline
\end{tabular}

$*$ Pec med $=$ medial pectoral nerve; rad $=$ radial nerve.

$\dagger$ Glenohumeral abduction (Case 2) $45^{\circ}$, (Case 5) $45^{\circ}$, (Case 6) $30^{\circ}$, (Case 12) $40^{\circ}$, and (Case 16) $50^{\circ}$.

\$ Glenohumeral exorotation (Case 11) $45^{\circ}$, (Case 12) $60^{\circ}$, and (Case 16) $70^{\circ}$.

TABLE 4

Combined accessory, hypoglossal or intercostal nerve transfer to suprascapular and/or axillary nerve in eight patients*

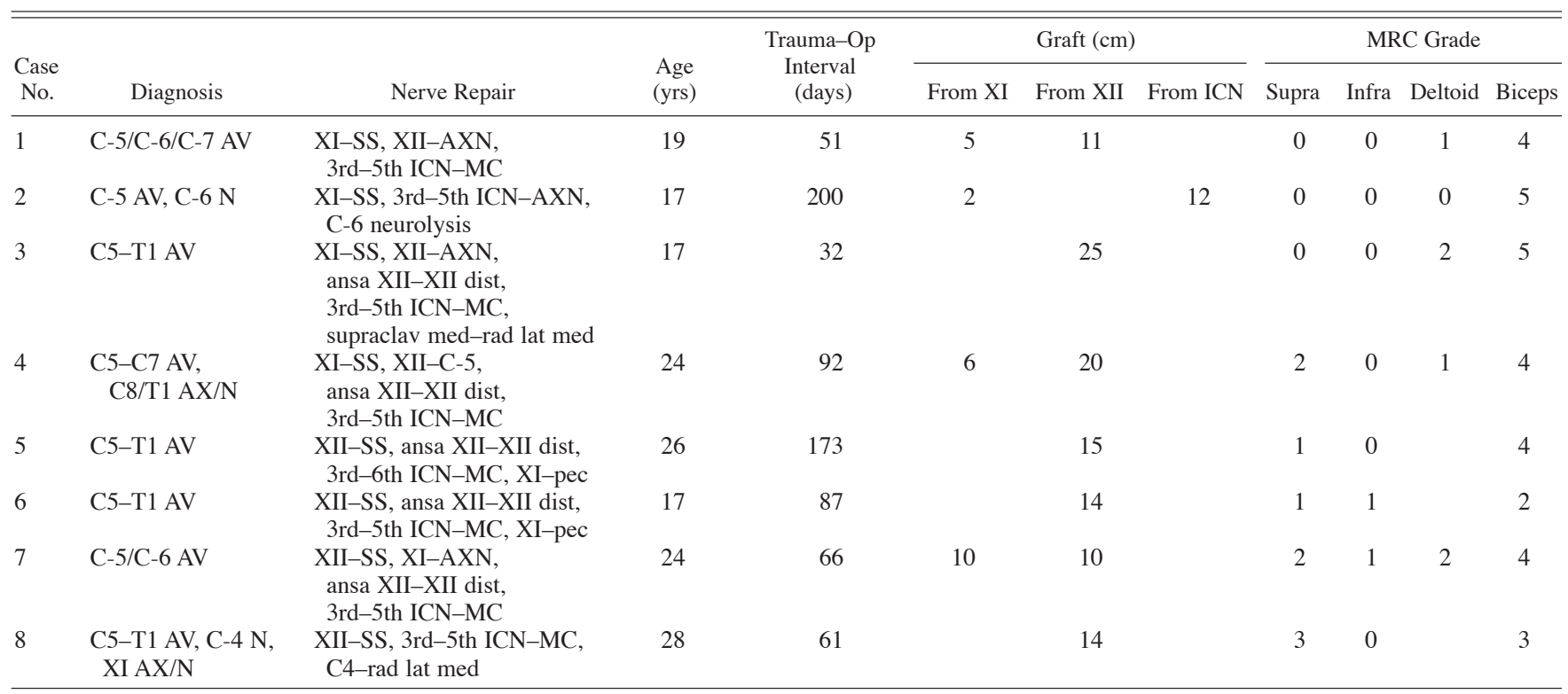

* ansa = cervical ansa hypoglossal nerve; $\mathrm{AXN}=$ axillary nerve; dist = distal branch; $\mathrm{SS}=$ suprascapular nerve; supraclav med = supraclavicular nerve; $\mathrm{XI}=$ accessory nerve 

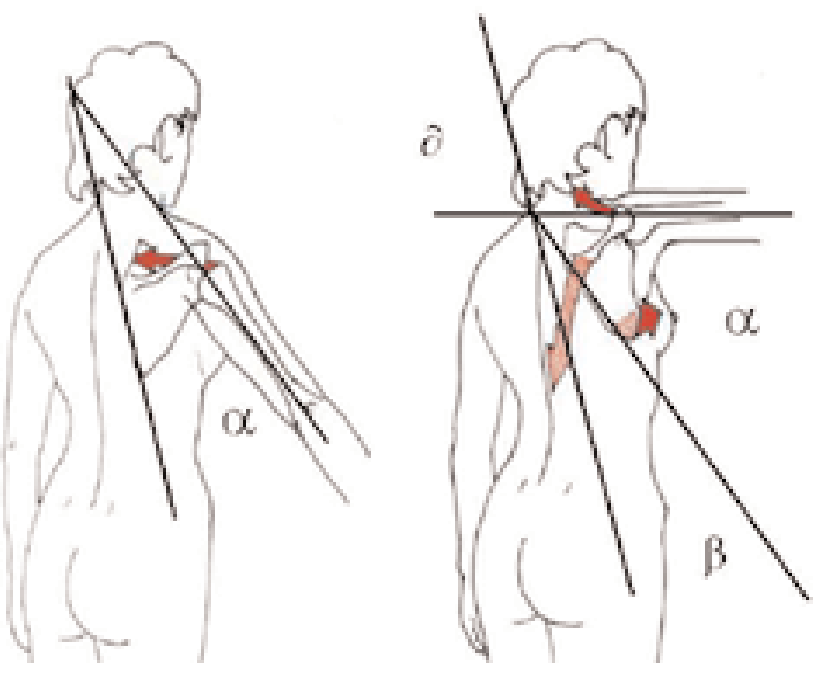

Fig. 1. The active range of abduction and exorotation was divided in two distinct parts: true glenohumeral motion and the total ROM, which combines the glenohumeral excursion and thoracoscapular rotations. True glenohumeral abduction occurs in the frontal plane and was defined as the angle $\alpha$ formed by the position of the humerus and the medial scapular margin at maximal abduction. Thoracoscapular rotation was defined as the angle $\beta$ formed by the position of the medial scapular margin at rest and at maximal abduction. This was measured by simultaneous palpation of the upper part of the extended arm with one hand and the inferior angle of the scapula with the other during an attempt of maximal abduction. The total functional abduction range $\partial$ is defined as the sum of $\alpha$ and $\beta$.

by the emptiness of the intervertebral foramen. In the case of nerve rupture, the neuroma was excised, and additional resection of scarred nervous tissue was based on the appearance of the nerve stump. In the case of neuromaincontinuity, ES of spinal nerves muscles was applied. General anesthesia did not include muscle blocking agents. If corresponding muscle contractions were absent, resection was continued until the architecture of the crosssectional area appeared normal through the operating microscope. Frozen-section examination was used to assess fibrosis/neuroma in the C-5 and/or C-6 proximal stump. In addition, a neuropathologist assessed the total quantity of myelin, represented by the stained myelin of the fibers, in the entire cross-sectional area of the donor stump semiquantitative. The results were classified as follows: a) less than $25 \%$; b) greater than or equal to $25 \%$ but less than $50 \%$; c) greater than or equal to $50 \%$ but less than $75 \%$; d) greater than or equal to $75 \%$. The amount of stained myelin in a normal spinal nerve is $100 \% .{ }^{20}$

In all cases, the priority of repair was restoration of biceps function. The decision-making process is schematically depicted in Fig. 4. If only one spinal nerve emerged from the intervertebral foramen (most often C-5), it was used to reinnervate the biceps preferentially if the following criteria were met. 1) Computerized tomography myelography demonstrated intact roots. 2) The fascicular pattern of the nerve cross-section on frozen examination appeared normal. 3) The frozen section showed more than $50 \%$ myelin and only slight fibrosis. ${ }^{20} 4$ ) The size of the cross-sectional area was equal to or larger than musculo-

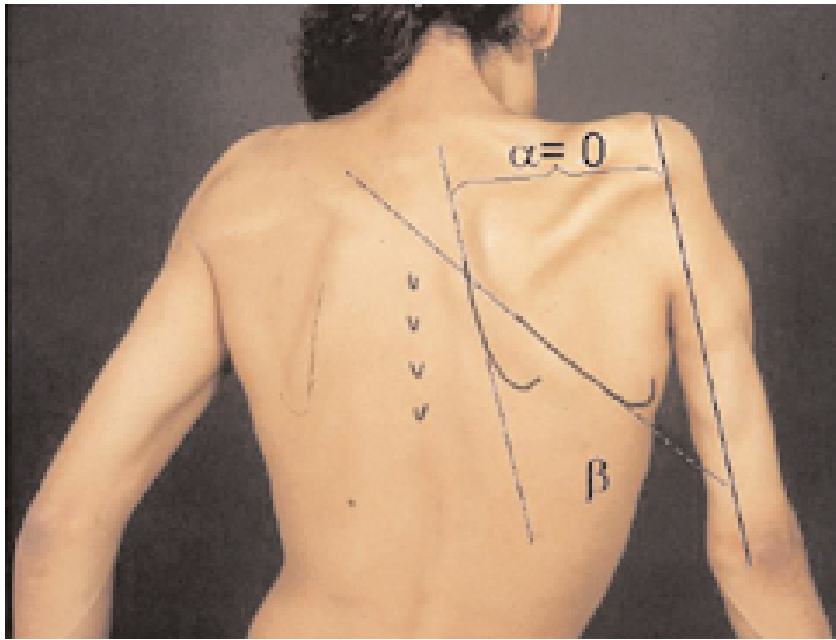

Fig. 2. Photograph of a 23-year-old patient with a severe brachial plexus traction lesion with $\mathrm{C}-5$ spinal nerve rupture and $\mathrm{C}$ 6 avulsion. Nerve grafting from C-5 to both suprascapular nerve and musculocutaneous nerve was performed. Supraspinatus and infraspinatus muscles strength recovered to MRC Grade 1. Glenohumeral abduction is $0^{\circ}$ and thoracoscapular rotation $\beta$ is \pm $40^{\circ}$. In an attempt to compensate for the lack of glenohumeral abduction, some abduction is achieved based on thoracoscapular rotation with intact trapezius, levator scapulae, rhomboid, and serratus anterior muscles in combination with lateroflexion of the spine. We do not consider this type of postoperative function a result of the procedure.

cutaneous nerve fascicles in the lateral cord or musculocutaneous nerve stump. If both C-5 and C- 6 contained myelinated fibers, C- 6 was selected to reinnervate the biceps when the quantity of myelin was equal to or greater than that of C-5 and when the cross-sectional area was equal to or larger than $\mathrm{C}-5$. When only one stump was available, most often $\mathrm{C}-5$, it was exclusively used for biceps muscle reanimation when the C-5 cross-sectional area was equal to that of the musculocutaneous nerve fas-
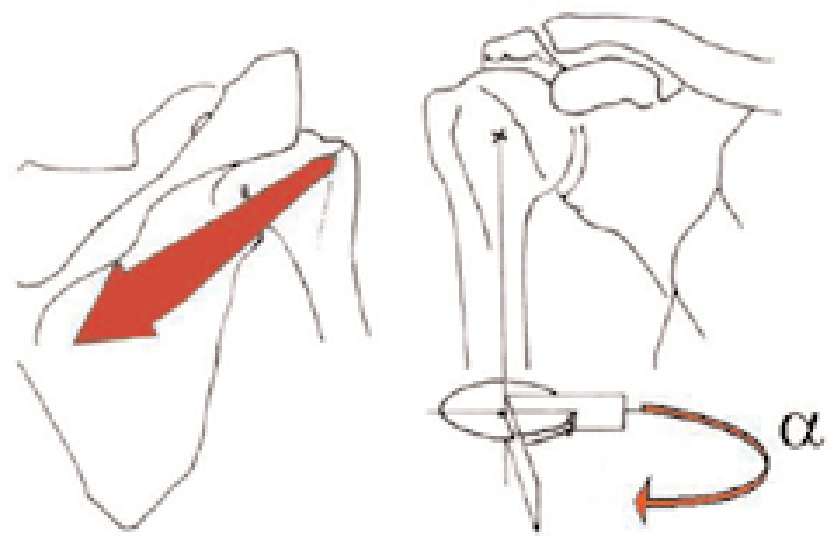

Fig. 3. True glenohumeral exorotation is defined as the angle between the position of the $90^{\circ}$ (actively or passively) flexed elbow resting against the belly and the position of the flexed elbow after exorotation with the upper arm in adduction until the scapula starts rotating. 
M. J. A. Malessy, et al.

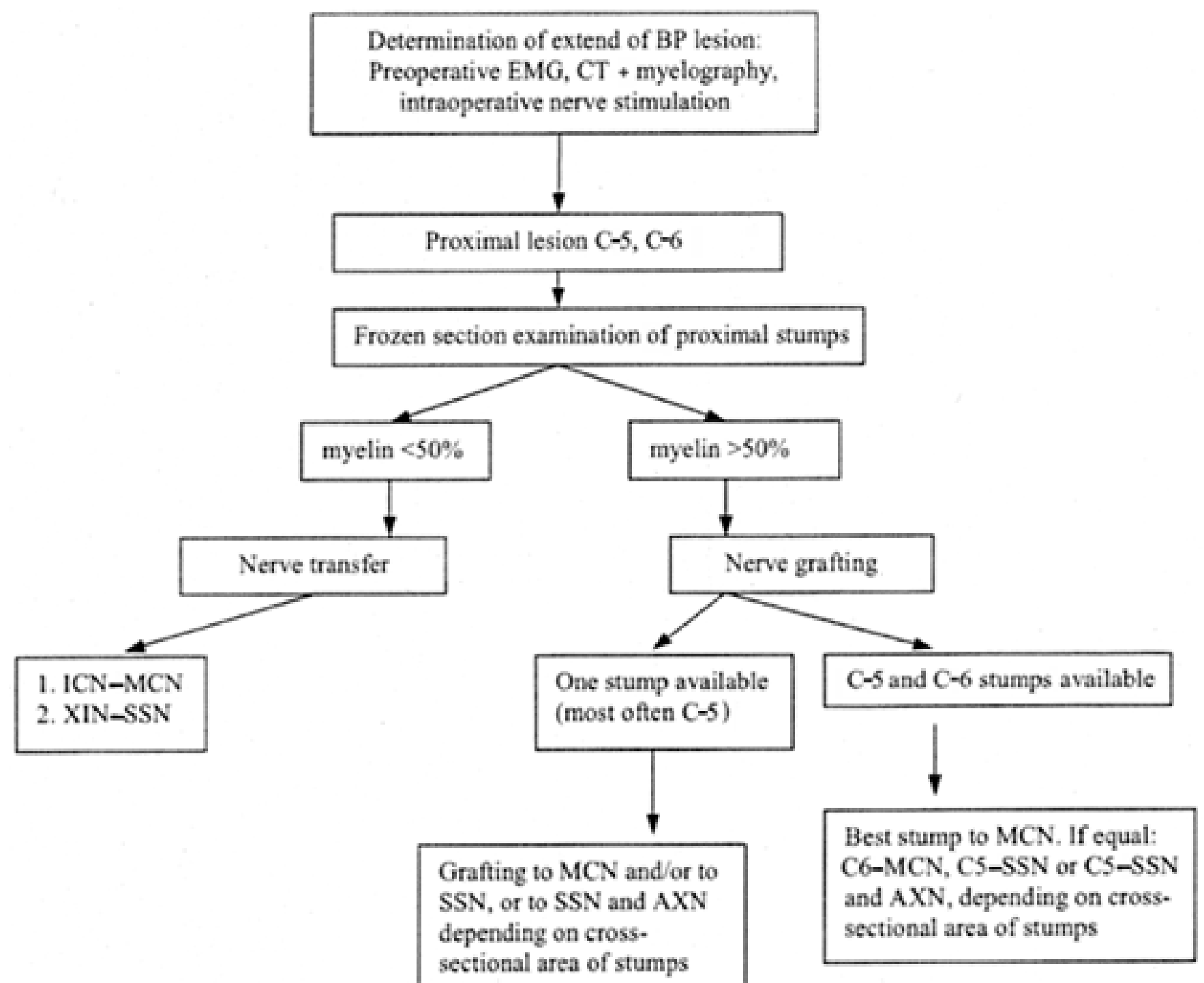

Fig. 4. Flow diagram depicting the applied surgery-related decision-making process. A C5-suprascapular nerve graft was performed in addition to grafting from C-5 to musculocutaneous nerve fascicles when the C-5 cross-sectional area was larger than that of the musculocutaneous nerve fascicles in the lateral cord or musculocutaneous nerve distal stump. One single graft was led out from C-5 to suprascapular nerve when the C-5 cross-sectional area equaled that of the suprascapular nerve and frozen-section analysis showed preferentially more than $50 \%$ myelin. Grafts were led from $\mathrm{C}-5$ to both the suprascapular nerve and axillary nerve when the C-5 cross-sectional area was large enough for the coaptation of more than two grafts and $\mathrm{C}-5 \mathrm{did}$ not fit the criteria for biceps muscle reinnervation. $\mathrm{AXN}=$ axillary nerve; $\mathrm{BP}=$ brachial plexus; C-5 = C-5 donor stump; C-6 = C-6 donor stump; ICN-MCN = intercostal to musculocutaneous nerve transfer; $\mathrm{XIN}-\mathrm{SSN}=$ accessory to suprascapular nerve transfer.

cicles in the lateral cord or musculocutaneous nerve distal stump.

The proximal C-5 stump was used as a lead-out for a graft to the suprascapular nerve in the following situation. First, C5-suprascapular nerve grafting was undertaken in addition to grafting from C-5 to musculocutaneous nerve fascicles when the C-5 cross-sectional area was larger than that of the musculocutaneous nerve fascicles in the lateral cord or musculocutaneous nerve distal stump. Second, a single graft was led out from C-5 to the suprascapular nerve when the C-5 cross-sectional area equaled that of the suprascapular nerve and the frozen-section examination showed preferentially more than 50\% myelin. ${ }^{20}$ Grafts were led from C-5 to both the suprascapular nerve and axillary nerve when the C- 5 cross-sectional area was large enough for the coaptation of more than two grafts and C-5 did not fit the aforementioned criteria for biceps muscle reinnervation. The donor C-5 stump was not used as a donor site for grafts when frozensection examination of specimen up to the foramen continued to show predominant neuromatous tissue or revealed ganglion cells.

For distal coaptation, maximal attempts were undertaken to reduce the gap between C-5 and both the supras- 
capular nerve and axillary nerve. Therefore, the retro- or infraclaviculary displaced suprascapular nerve stump was neurolyzed and transposed back to the original supraclavicular region as far up as possible. Far distal dissection to exclude a two-level lesion of the suprascapular nerve, for instance by rupture out of the supra- and infraspinatus muscles or rupture at the level of the scapular notch, was not systemically performed. The axillary nerve was cut as proximally as possible after freeing it from the posterior cord until fascicular intermingling with thoracodorsal or radial nerve fascicles was encountered. Incidentally, the axillary nerve fascicles could be freed up to the level of the distal part of the posterior division of the superior trunk, which was then the level of distal coaptation. In the majority of cases cabled sural grafts were used to bridge the gap. The length of the graft was documented in the operative record. Coaptations were secured by means of 10-0 sutures and/or fibrin glue.

These nerve reconstructive procedures were part of an extended brachial plexus reconstruction, including, for example, intercostal-musculocutaneous nerve transfer (Tables 1 and 2).

Nerve Transfer. The accessory-suprascapular nerve transfer was applied when both C-5 and C-6 were avulsed or when one proximal stump was available. This stump was preferentially used for biceps muscle reinnervation and not for shoulder reanimation when it fitted the criteria mentioned above. The accessory nerve distal to the innervating branch of the sternocleidomastoid muscle was followed in its trajectory through the posterior triangle of the neck. The status of the accessory nerve was assessed using ES. The accessory nerve transfer procedure was abandoned when the preoperative neurological examination showed weakness of the trapezius muscle, and this was confirmed by weak trapezius contractions following accessory nerve ES. Our intention was to perform a direct coaptation between the accessory nerve and suprascapular nerve. To achieve this, two steps were taken. First, the retro- or infraclaviculary displaced suprascapular nerve stump was neurolyzed and transposed back to the original supraclavicular region as far up as possible. Second, the entire trajectory of the accessory nerve distal from the branch to the upper part of the trapezius muscle was exposed and transected as distally as possible. The accessory nerve was then transferred to the lateral neck region. Both stumps were coapted using 10-0 sutures and/or fibrin glue.

In eight patients with at least C-5 and C-6 avulsion we have used either the hypoglossal nerve or intercostal nerve transfer for shoulder function reanimation, which was in addition to accessory nerve transfer in five of these patients. The surgical technique, which was used to dissect free and transfer the hypoglossal nerve or intercostal nerves, has been described previously. ${ }^{17,18}$

\section{Intraoperative Findings}

Of the 53 patients, 15 presented with rupture of C-5 and 20 with rupture of both C-5 and C-6. Thirty-two C-5 and 15 C-6 stumps were used as donor sites for grafts. Advanced resection of the remaining C-5 and C-6 stumps up to the intervertebral foramen continued to reveal fibrosis and no myelin. One patient was shown to have an avulsion of C-5, and 17 had an avulsion of both C-5 and C-6, as was confirmed by the emptiness of the intervertebral foramen. The C7-T1 spinal nerves were totally avulsed in 21 patients (Tables 1-4).

\section{Reconstructive Procedures}

Overall, 59 grafting procedures and 85 transfers were performed in the group of 53 patients. The specifications of the brachial plexus reconstructions of each individual patient are summarized in Tables 1 to 4 . A C-5 proximal stump was available for grafting in 32 patients. Adhering to the decision-making process illustrated in Fig. 4, eight C-5 stumps (25\%) were exclusively used for biceps muscle reinnervation.

In 24 patients the $\mathrm{C}-5$ was used as a lead out for a graft to the suprascapular nerve (Tables 1 and 2). In 11 of these patients, the C5-suprascapular nerve grafting was the only procedure for the reanimation of active glenohumeral shoulder function. These cases will be referred to as the C5-suprascapular nerve group (Table 1). In the remaining 13 patients, C5-axillary nerve grafting was performed in addition to the C5-suprascapular nerve grafting. These cases will be referred to as the C5-suprascapular nerve and axillary nerve group (Table 2). Nerve transfers to the suprascapular nerve were performed in 26 patients. Additional grafting procedures or transfers such as intercostal to medial pectoral have been performed as well, but their evaluation is beyond the scope of this study.

\section{Grafting of C-5 to Suprascapular Nerve}

In five of the 11 patients in this group (Table 1), only one graft fit the cross-sectional area of the C-5 stump. The C5-suprascapular nerve grafting was performed in addition to grafting to the anterior division of the superior trunk, lateral cord or musculocutaneous nerve in the remaining six patients. Values are presented as the means \pm SD. The mean C5-suprascapular nerve graft length was $5.1 \pm 1.9 \mathrm{~cm}$ (median $5 \mathrm{~cm}$ ). The total quantity of myelin in the entire cross-sectional area of the C-5 donor stump was equal to or greater than $50 \%$ in eight of 10 patients and was not available in one. The mean age at surgery was $26.5 \pm 12.2$ years (median 22 years). The mean interval between trauma and operation was $125.7 \pm 71.7$ days (median 131 days) The mean follow-up period was $2.8 \pm$ 0.9 years (median 2.9 years).

\section{Grafting of C5 to Suprascapular Nerve and Axillary Nerve}

In this group of 13 patients (Table 2), the mean graft length from $\mathrm{C}-5$ to the suprascapular nerve was $6.3 \pm 1.5$ $\mathrm{cm}$ (median $6 \mathrm{~cm}$ ). The mean number of grafts from C-5 to the axillary nerve was $1.8 \pm 0.7$ (median 2), and the mean graft length was $10 \pm 2.4 \mathrm{~cm}$ (median $10.5 \mathrm{~cm})$. The total quantity of myelin in the entire cross-sectional area of the C-5 donor stump was equal to or greater than $50 \%$ in nine $(70 \%)$ of the patients. The mean age at surgery was $25.5 \pm 8.3$ years (median 23.5 years). The mean interval between trauma and operation was $151.7 \pm 87.5$ days (median 129 days). The mean follow-up period was $2.4 \pm$ 0.9 years (median 2.4 years). 


\section{Transfer of Accessory Nerve to Suprascapular Nerve}

The accessory nerve-suprascapular nerve transfer was the only procedure for shoulder function reanimation in 21 patients (Table 3 ). Nine patients were shown to have C5-T1 avulsion and 12 had rupture or avulsion of C-5 and avulsion of C-6 (C-7).

The mean age at surgery was $24.3 \pm 7.3$ years (median 23.3 years). The mean interval between trauma and operation was $128.4 \pm 63.5$ days (median 121 days). The mean follow-up period was $4 \pm 2.3$ years (median 3.1 years).

\section{Combined Accessory Nerve, Hypoglossal Nerve, or Intercostal Nerve Transfer to Suprascapular Nerve and Axillary Nerve}

In this group of eight patients, accessory nerve-suprascapular nerve transfer in combination with hypoglossal nerve or intercostal nerve transfer to the axillary nerve was conducted four times. The hypoglossal nerve-suprascapular nerve transfer was performed in four patients and combined with accessory nerve-axillary nerve transfer in one patient (Table 4). The mean graft length from the hypoglossal nerve to the distal targets was $15.6 \pm 5.3 \mathrm{~cm}$ (median $14 \mathrm{~cm}$ ). The mean age at surgery was $21.5 \pm 4.4$ years (median 21.4 years). The mean interval between trauma and operation was $95.3 \pm 59.9$ days (median 76.5 days). The mean follow-up period was $3.2 \pm 0.6$ years (median 3.3 years).

\section{RESULTS}

\section{All Groups}

Postoperative needle EMG studies showed polyphasic action potentials and recruitment patterns as befitting reinnervation in the supraspinatus muscle in $43(84 \%)$ of 51 available examinations. In nine $(17 \%)$ of 53 patients supraspinatus muscle strength of MRC Grade 3 or 4 was demonstrated. Electromyography studies of the infraspinatus muscle showed reinnervation in 37 (74\%) of 50 examinations. In four $(8 \%)$ of the 53 patients infraspinatus muscle force of MRC Grade 3 or 4 was achieved. Deltoid muscle reinnervation was attempted in 18 patients. In 15 (88\%) of 17 available studies EMG showed reinnervation. Two patients (11\%) exhibited MRC Grade 3 or 4 function.

In the total group, eight patients (15\%), achieved glenohumeral abduction $(\alpha)$ with a mean of $44 \pm 17^{\circ}$ (median $45^{\circ}$ ), and four patients $(8 \%)$ exhibited glenohumeral exorotation $(\alpha)$ with a mean of $48 \pm 24^{\circ}\left(\right.$ median $\left.53^{\circ}\right)$. Only three patients $(6 \%)$ regained both functions. Thirty-six $(68 \%)$ of 53 patients exhibited biceps muscle force of MRC Grade 3 or 4.

\section{Grafting of C-5 to Suprascapular Nerve}

In this group, postoperative needle EMG of the supraand infraspinatus muscle demonstrated reinnervation in nine of 10 available studies. Despite this evidence of restored neural continuity to the suprascapular nerve, only one $(9 \%)$ of 11 patients exhibited supraspinatus muscle strength of MRC Grade 3: glenohumeral abduction $(\alpha)$ was $20^{\circ}$ and total abduction (d) was $45^{\circ}$ (Table 1 ).
Glenohumeral abduction did not recover in the remaining 10 patients. Restoration of active exorotation did not occur in any of the 11 patients; however, in seven (64\%) biceps muscle strength of MRC Grade of 3 or greater was shown.

\section{Grafting of C-5 to Suprascapular Nerve and Axillary Nerve}

In this group, postoperative needle EMG of the supraand infraspinatus muscle showed reinnervation in eight (67\%) of 12 available studies. Electromyography of the deltoid muscle showed reinnervation in $10(83 \%)$ of the 12 examinations. Two (15\%) of the 13 patients exhibited some supraspinatus muscle strength, one MRC Grade 3, and one Grade 4 (Table 2). Deltoid muscle recovery of MRC grades 3 and 4, respectively, occurred only in these two patients. The glenohumeral abduction $(\alpha)$ was $45^{\circ}$ in one patient and $80^{\circ}$ in the other.

One patient $(8 \%)$ exhibited infraspinatus muscle force of MRC Grade 3. The glenohumeral exorotation $(\alpha)$ was $15^{\circ}$. Seven patients (54\%) exhibited biceps muscle force of MRC Grade 3 or greater.

\section{Accessory Nerve-Suprascapular Nerve Transfer}

Postoperative needle EMG of the supraspinatus muscle showed reinnervation in $18(85 \%)$ of the 21 patients; EMG of the infraspinatus muscle showed reinnervation in $14(70 \%)$ of 20 available examinations. Only five (24\%) of the 21 patients, however, exhibited supraspinatus muscle strength MRC Grade 3 or 4 . Infraspinatus muscle force in three patients $(14 \%)$ was MRC Grade 3 or 4 . Fifteen patients $(71 \%)$ exhibited biceps muscle force of MRC Grade 3 or 4 (Table 3 ).

Nerve grafting was necessary to bridge the gap between the accessory nerve and the suprascapular nerve in five $(24 \%)$ of 21 patients. The mean length of the grafts was $5 \pm 1.4 \mathrm{~cm}$ (median $6 \mathrm{~cm}$ ). In these five patients none exhibited supra- or infraspinatus muscle force of MRC Grade 3 or higher.

In $16(76 \%)$ of the 21 patients direct coaptation of accessory nerve to suprascapular nerve was achieved. In five $(31 \%)$ of the 16 patients supraspinatus muscle force of MRC Grade 3 or more was demonstrated. In terms of function, only four patients (25\%) exhibited glenohumeral abduction $(\alpha)$ of $\pm 45^{\circ}$, which could only be effected by supraspinatus muscle contraction. The total functional abduction range (J) was 60 to $90^{\circ}$ when thoracoscapular rotation was included. Infraspinatus muscle force in three patients (19\%) was MRC Grade 3 or greater. Glenohumeral exorotation in the range from the umbilicus outward was 45,60 , and $70^{\circ}$, respectively. Of the 16 patients who underwent direct accessory nerve-suprascapular nerve coaptation, both supra- and infraspinatus function of MRC Grade 3 or higher was achieved in only two (13\%) (Fig. 5 upper and lower).

Although we did not systematically study the scapular position at rest before and after nerve transfer, we noted a postoperative change in the scapular position in 14 patients. In four patients the scapula had moved upward, and in five patients the inferior angle was laterally rotated. In three patients the scapula had an elevated and laterally rotated position. In the remaining two patients the scapula 


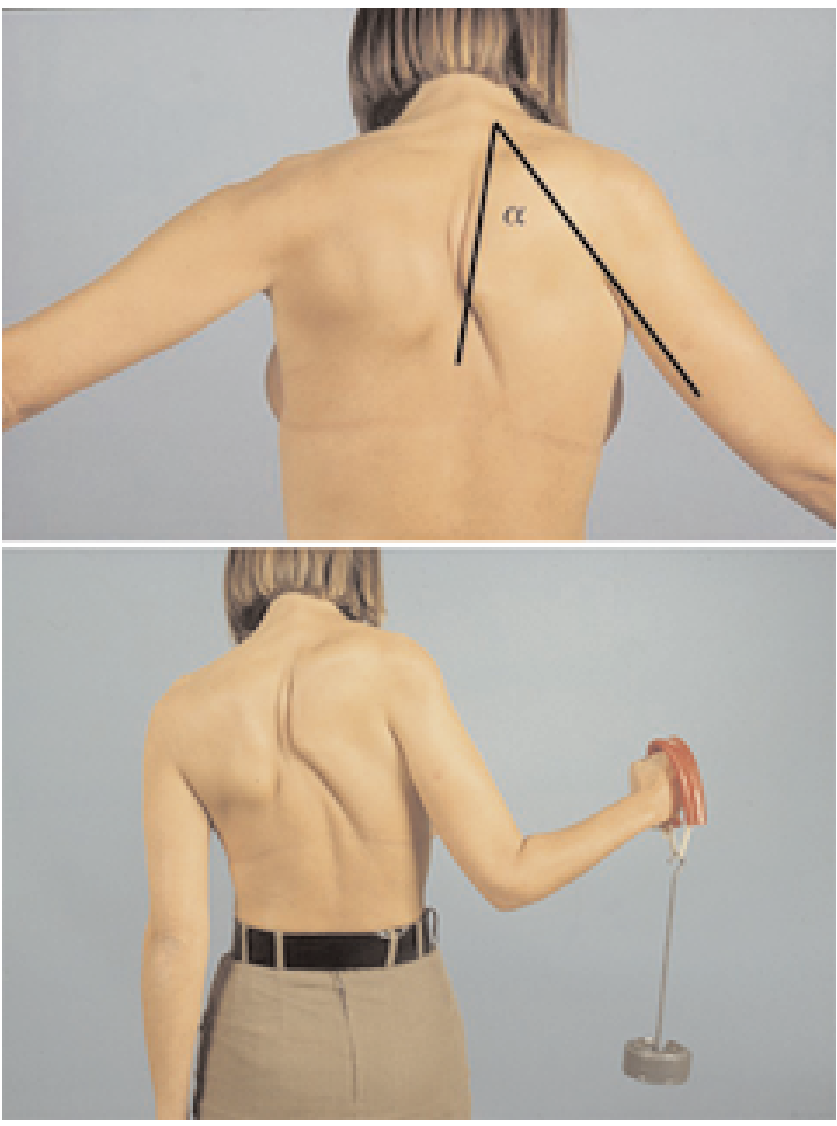

Fig. 5. Photographs of a 33-year-old woman with a severe brachial plexus traction lesion with intraforaminal rupture of the $\mathrm{C}$ 5 spinal nerve and of C-6 and C-7 avulsion. Accessory to suprascapular nerve transfer and intercostal to musculocutaneous nerve transfer was performed 147 days after trauma. Direct coaptation of accessory nerve to suprascapular nerve was achieved. The supraspinatus muscle recovered to MRC Grade 4 and the infraspinatus to Grade 3. Upper: Glenohumeral abduction is $40^{\circ}$. Lower: Combined abduction and exorotation. Only two (13\%) of the 16 patients with direct accessory nerve-suprascapular nerve coaptation exhibited MRC Grade 3 or better function of the supra- and infraspinatus muscles.

had moved medially. All of these patients exhibited normal postoperative function of the serratus anterior and rhomboid muscles. Fifteen $(71 \%)$ patients of the overall 21 patients exhibited biceps muscle force of MRC Grade 3 or greater.

\section{Combined Accessory Nerve, Hypoglossal Nerve, or Intercostal Nerve Transfer to Suprascapular Nerve And Axillary Nerve}

In this group, postoperative needle EMG of the supraspinatus muscle showed reinnervation in all eight patients and infraspinatus muscle reinnervation in six $(75 \%)$ of these patients. Electromyography of the deltoid muscle showed reinnervation in all five patients in whom reinnervation was attempted. Only one of the patients in this group had supraspinatus muscle force MRC Grade 3, after a hypoglossal nerve-suprascapular nerve transfer (Table 4); however, the restored supraspinatus muscle force did not result in functional abduction because volitional control was not restored. The successfully reinnervated muscle could only be contracted by forceful pressure of the tongue against the hard palate or inner wall of the cheek. Infraspinatus muscle recovery greater than MRC Grade 1 occurred in no patient. Combinations of hypoglossal nerve transfer with transfer of the accessory nerve or intercostal nerves did not lead to glenohumeral abduction or exorotation. Seven patients (88\%) exhibited biceps muscle force of MRC Grade 3 or greater.

\section{Elbow Flexion}

Nerve grafting was aimed at recovery of biceps muscle function in 28 patients of the total group of 53 patients. Eighteen $(64 \%)$ of them attained biceps muscle strength MRC grades of 3 or greater. The intercostal nerve-musculocutaneous nerve transfer was performed in 21 patients. Fourteen patients (67\%) achieved biceps muscle force of MRC grades of 3 or more (Tables 1-4).

\section{DISCUSSION}

We report the results obtained in 53 patients who harbored intra- or juxtaforaminal neurotmetic lesions or avulsion of C-5 and C-6 in combination with scarring-induced loss of the superior trunk. The primary goal of reconstruction was restoration of elbow flexion. After grafting, $64 \%$ of the patients recovered biceps muscle function of MRC Grade 3 or 4 , and after intercostal nerve-musculocutaneous nerve transfer $67 \%$ of the patients regained this function. This outcome differs slightly from those in two previous studies conducted by our group, which were 74 and $64 \%$, respectively. ${ }^{18,20}$ Different patient inclusion criteria were used for each study. The aim of the present study was, however, to evaluate the restoration of shoulder function, which was the second goal of nerve repair. Reanimation of shoulder function was primarily pursued by suprascapular nerve neurotization. Repair techniques included grafting from C-5 spinal nerve to the suprascapular nerve; accessory nerve to suprascapular nerve transfer; and hypoglossal nerve to suprascapular nerve transfer. In 18 patients additional neurotization of the axillary nerve was performed as well.

Postoperative needle EMG studies of the supraspinatus, infraspinatus, and deltoid muscles revealed signs of reinnervation in the majority of the patients; however, active glenohumeral shoulder function recovery was poor. Comparison of our results with previous reports is difficult because of patient heterogeneity and incomplete specification of lesions and repairs in these studies.

In the present series, several factors independent of the applied repair technique can be identified that may account for the poor shoulder function recovery. First, the relatively poor outcome may be due to the data analysis. We adapted our evaluation concept from Narakas ${ }^{23}$ who emphasized the distinction between true glenohumeral motion and the total ROM, the latter including thoracoscapular movement. Supraspinatus, infraspinatus, and deltoid muscles are involved in glenohumeral motion while trapezius, levator scapulae, rhomboid, and serratus anterior muscles control the scapular thoracic motion. ${ }^{26}$ If supraspinatus, infraspinatus, and deltoid muscles are paralyzed, functional abduction over a range of $\pm 45^{\circ}$ is 
based on thoracoscapular rotation (Fig. 2). We do not consider this type of postoperative function a result of the surgical procedure. ${ }^{10}$ Second, we reported on a selected group of upper plexus lesions, in which cases involving with a distally located brachial plexus lesion affecting shoulder function were excluded. Recovery after nerve repair is better in the latter group because of the absence of root avulsion and a shorter distance of the lesion to the target muscle. ${ }^{33}$ This may explain the superior results in combined series. ${ }^{35}$ Third, we did not routinely dissect the suprascapular nerve up to the level of the scapular notch. Therefore, we may have missed two-level lesions of the suprascapular nerve. In our experience it is technically difficult to assess the status of the suprascapular nerve at the notch level via the anterior approach because the level of the notch is relatively deep. Because the incidence of two-level suprascapular nerve lesions in BPTIs has never been systematically analyzed, we do not know to what degree, if any, this factor accounts for our failures.

Fourth, plain x-ray films demonstrated scapular fractures or humeral fractures in nine patients $(17 \%)$. It appears that scapula and/or proximal humerus fractures are frequently associated with soft-tissue lesions at the glenohumeral joint. ${ }^{30}$ These lesions may certainly affect outcome after nerve repair. We have not routinely performed MR imaging investigations of the shoulder prior to surgery and we may, therefore, have missed soft-tissue pathological entities. For future reference, it may be advisable to undertake MR imaging of the shoulder, or even arthroscopy, prior to nerve surgery when the scapula or humerus has been fractured.

Fifth, there is inherent variability in the normal supraspinatus muscle function. The supraspinatus muscle is known to be primarily active during the initial phase of abduction. Function, therefore, is synergistic with the deltoid muscle. ${ }^{12}$ Some of the patients with isolated lesions of the axillary nerve, however, exhibited a normal abduction range, ${ }^{4}$ which we have also observed. Others may only be able to abduct the arm over a range of $\pm 30^{\circ}$, although the long portion of the biceps is also involved in trick movements to compensate for the loss of deltoid function. ${ }^{2}$ Because the range of abduction executed by the supraspinatus muscle alone may vary among individuals, the results of suprascapular nerve neurotization may inherently vary as a consequence.

\section{Nerve Grafting to the Suprascapular Nerve}

Different factors may account for the poor functional outcome after the C5-suprascapular nerve grafting that was performed in 24 patients. In grafting for restoration of biceps muscle function, it has been shown that an increase of myelin in the proximal stump is positively correlated to an increase in force. ${ }^{20} \mathrm{~A}$ similar relationship for C5-suprascapular nerve grafting is likely. In the present series, the majority of the C-5 stumps contained more than $50 \%$ of the normal level of myelin $;{ }^{20}$ however, five C-5 stumps could serve as a donor site for only one graft. In general, the cross-sectional area of C-5 is three- to fivefold greater than that of the sural nerve. The cross-sectional area of the C-5 stumps in these five patients may have been reduced. Only one of the five patients regained some abduction. A reduction of the cross-sectional area may, therefore, be indicative of a degraded regenerative motor potency. In addition to grafting to the suprascapular nerve, C-5 was used for elbow flexion in six patients. None of these patients regained active glenohumeral shoulder function; however, functional biceps muscle recovery occurred in three of these six patients. Therefore, outcome of shoulder function recovery cannot only be attributed to the regenerative potency of the C-5 outlet. Theoretically, when the C-5 cross-sectional area is large enough to coapt several nerve grafts, there should be an optimal position to attach the graft to the C-5 stump to reduce misrouting of the original suprascapular nerve axons. This position is the fascicular C-5 area where these axons are already (partially) grouped to form the suprascapular nerve branch. It may be that the amount of fascicular orientation of the original suprascapular nerve axons at the transection level of the C-5 stump affects the results of C5-suprascapular nerve grafting. Moreover, the determination of the position of the graft to the suprascapular nerve on the C-5 stump is arbitrary. The graft to the suprascapular nerve may unintentionally be coapted to a fascicular C-5 area without original suprascapular nerve axons. To the best of our knowledge, the fascicular orientation of suprascapular nerve axons over the length of the C-5 spinal nerve has not been systematically examined. Additionally, should an optimal fascicular suprascapular nerve area at the juxtaforaminal level indeed exist, it has not been determined whether, for instance, it is located in the cranial or caudal aspect of the C-5 stump.

Grafting to both suprascapular nerve and axillary nerve from C-5 was performed in another group of 13 patients in whom, in the majority, C- 6 was available for grafting to restore biceps function. In this group the results of shoulder function recovery were not much better than after single suprascapular nerve neurotization - that is, there was no effect of the additional deltoid reinnervation. This might be explained by the length of the grafts (mean $10 \pm$ $2.4 \mathrm{~cm}$ [median $10.5 \mathrm{~cm}$ ]), which we had to use to bridge the C5-axillary nerve gap. It appears that the potential for deltoid muscle recovery is limited when long grafts have to be used to bridge a gap between $\mathrm{C}-5$ at the juxtaforaminal level and the axillary nerve.

We found only one study in which C5-suprascapular nerve grafting was reported. ${ }^{3}$ Those patients, in whom very good function recovery occurred, exhibited an external rotation of $30^{\circ}$. In addition, return of shoulder stability was claimed to be the result of the reconstruction. In our opinion, it is difficult to attribute the transformation of a subluxed glenohumeral joint into a stable joint to successful suprascapular nerve neurotization when multiple nerve repairs have been performed. Simultaneous reinnervation of the long head of the biceps muscle also contributes to shoulder stability. We do not believe, therefore, that shoulder stability should be the goal for suprascapular nerve neurotization, either by grafting or transfer.

We conclude that grafting from C-5 to the suprascapular nerve with, if the occasion arises, grafting to the axillary nerve, is of limited value.

\section{Nerve Transfer}

At present, the accessory nerve-suprascapular nerve transfer is widely regarded as a potential nerve recon- 
structive technique to restore active shoulder function in cases of severe BPTIs with upper nerve root avulsion. In 1993 we reported our initial results on the accessory nerve-suprascapular nerve transfer in a small group of patients. ${ }^{36}$ Probably all centers with extensive experience in surgical nerve treatment of brachial plexus lesions use this transfer. ${ }^{13}$ To date, there have been seven studies pertaining to the results of shoulder function; in which recovery was attributed to the accessory nerve-suprascapular nerve transfer. These studies comprise only 75 patients overall. ${ }^{1,5,7,9,10,21,25}$ The differing results are shown in Table 5. Results of a metaanalysis ${ }^{21}$ indicated that the accessory nerve-suprascapular nerve transfer is an effective repair technique; however, the indications for surgery in the various studies differed, and the results were not analyzed or presented uniformly. Birch, et al., ${ }^{4}$ reported on 156 accessory nerve-suprascapular nerve transfers, the largest series published to date. Supraspinatus and infraspinatus muscle force of MRC Grade 3 or higher was achieve in approximately two thirds of the patients. It is difficult to compare their series with ours because the extent of the lesions was not specified in detail and reconstructive procedures also included superior trunk grafting. The short interval between trauma and surgery may have favored the outcome ${ }^{33}$ because some patients underwent surgery within 14 days after trauma. The mean interval between injury and surgery in our series was $128.4 \pm 63.5$ days (median 121 days).

In the present series the accessory nerve-suprascapular nerve transfer was performed in 21 patients. Additional reanimation of the deltoid muscle was not undertaken in this group. Although EMG signs of reinnervation were present in most patients, restoration of useful shoulder function was limited. Our intention was to perform a direct accessory nerve to suprascapular nerve coaptation. To achieve this goal, we always attempted to mobilize the retro- or infraclavicularly retracted suprascapular nerve to a supraclavicular level, to reduce the gap between the accessory nerve and suprascapular nerve. In addition, the accessory nerve was transected as far distally as was required for direct coaptation, or as was technically possible. Without exception, accessory nerve transection was performed distal to the site of nerve branching to the upper part of the trapezius muscle. This branching site thus

\section{TABLE 5}

Summary of reports involving accessory to suprascapular nerve tranfer*

\begin{tabular}{lcc}
\hline \hline \multicolumn{1}{c}{ Authors \& Year } & No. of Cases & MRC Grade $\geq 3(\%)$ \\
\hline Allieu \& Cenac, 1988 & 2 & $0(0)$ \\
Oberlin, et al., 1994 & 1 & $1(100)$ \\
Chuang, et al., 1995 & 25 & $\dagger$ \\
Bonnard \& Narakas, 1995 & 32 & $22(69)$ \\
Merrell, et al., 2001 & 6 & $3(50)$ \\
Dubuisson \& Kline, 2002 & 5 & $2(40)$ \\
El-Gammal \& Fathi, 2002 & 4 & $\ddagger$ \\
\hline
\end{tabular}

* Nerve repairs with neurotization of the trajectory to the axillary nerve were excluded.

$\dagger$ A 20 to $80^{\circ}$ abduction with a mean of $45^{\circ}$.

+ A mean of $30^{\circ}$ abduction. formed the proximal rotation point of the accessory nerve in the transfer.

Despite these efforts, a graft to connect the accessory nerve to the suprascapular nerve was required in approximately $25 \%$ of the patients (mean $5 \pm 1.4 \mathrm{~cm}$ [median 6 $\mathrm{cm}]$ ). In this graft group none of the patients exhibited MRC Grade 3 or better function in the supra- or infraspinatus muscles. Grafting is less effective than direct coaptation because regenerating axons have to cross two coaptation sites, at each of which the number of successfully regenerating axons will decrease..$^{33}$ Remarkably, three of the five patients had a flail arm. The severity of a brachial plexus lesion is related to the impact of the traction injury and complete lesions may, therefore, also be related to a more caudal displacement of the suprascapular nerve.

In $16(76 \%)$ of 21 patients direct coaptation of accessory nerve to suprascapular nerve was achieved. In approximately $25 \%$ of the group of patients with direct accessory nerve-suprascapular nerve coaptation glenohumeral abduction of $\pm 45^{\circ}$ was attained and in only $20 \%$ was glenohumeral exorotation $\pm 45^{\circ}$.

To understand the limited success of the accessory nerve-suprascapular nerve transfer, some factors intrinsically related to this procedure must be considered. First, very distal transection of the accessory nerve to obtain direct coaptation with the suprascapular nerve is a drawback of a decrease of motor axons at this level. Branches to the medial part of the trapezius muscle leave the main accessory nerve trunk along its trajectory. Very distal transection of the accessory nerve, therefore, enlarges the preexisting discrepancy between the normal number of nerve fibers of the suprascapular nerve (3800) and that of the accessory nerve at the proximal level (1700) ${ }^{6}$

Second, after cutting the accessory nerve, the trapezius denervation is unpredictable and may result in a medial rotation of the inferior angle of the scapula. This will reduce the range of abduction. We observed a postoperative change in scapular position at rest in 14 patients that was not consistent. It has been suggested that the inconsistent denervation is caused by the anatomical variability in the contribution of the cervical plexus to the accessory nerve; however, cadaver dissection has demonstrated that the role of these cervical plexus branches in trapezius innervation is negligible. ${ }^{8}$ The impact of this anatomical variability seems, therefore, to be of limited value. It is more likely that anatomical differences of the accessory nerve itself, in the number of branches and level of branching to the medial and inferior part of the trapezius, cause the unpredictable denervation.

Third, the restoration of function after nerve transfer requires cerebral plasticity to become functionally effective. ${ }^{16,19}$ The accessory nerve fibers used in the transfer normally innervate the medial and/or inferior parts of the trapezius muscle. Electromyography recordings have shown activity for all three trapezius parts during abduction movements. ${ }^{11}$ It seems, therefore, that there is a close relationship between the central control of the accessory nerve and suprascapular nerve. Plasticity in this study has not been systematically investigated; however, EMG recordings in some of our patients revealed activity in the supraspinatus muscle during attempts at abduction only in combination with attempts at elevating the shoulder (that 
is, selective abduction commands did not activate the supraspinatus muscle). These findings may indicate that central plastic changes after the transfer did not occur. Volitional control over the reinnervated supraspinatus muscle may therefore be limited. Furthermore, the suprascapular nerve contains axons for abduction and exorotation. This dual function may also hamper adequate cerebral control after accessory nerve-suprascapular nerve transfer. Indeed, in some of our patients' activity in the infraspinatus muscle could only be detected during attempts at abduction, and in the supraspinatus muscle of one patient only during an attempt at exorotation. To improve results of shoulder function recovery, we used the hypoglossal nerve as an additional extraplexal source of axons for transfer, in combination with the accessory nerve transfer or intercostal nerves (Table 4). Unfortunately, this did not result in shoulder-related functional improvement. In a recent anatomical study it was suggested that the hypoglossal nerve transection site might be a factor in the disappointing results of the hypoglossal nerve transfer because it affects the number of axons that become available for transfer. ${ }^{37}$ The major drawback of the use of the hypoglossal nerve, however, is that cerebral plastic changes for the regain of central control do not take place. After hypoglossal nerve transfer, a successfully reinnervated target muscle can only be contracted by forceful pressure of the tongue against the hard palate or inner wall of the cheek. Thus, the functional gain of hypoglossal nerve transfer was virtually nonexistent, despite target muscle recovery of MRC Grade 3 or greater. ${ }^{17}$

\section{Elbow Flexion}

Priority in grafting was given to elbow flexion reanimation. Therefore, it is not surprising that flexion recovery was superior to shoulder function recovery. Indeed, when proximal stumps were available for grafting, the stump with the largest quantity of myelin and a greater cross-sectional area was used for neurotization of the musculocutaneous nerve or lateral cord. It is more difficult to understand the discrepancy in results following nerve transfer for elbow flexion or for shoulder function. We used intercostal nerves as proximal outlet in the transfer for the biceps and the accessory nerve as proximal outlet for the shoulder. We have not systematically used intercostal nerves as a donor for shoulder function, nor have we used the accessory nerve for elbow flexion reanimation. This makes it difficult to compare the results of the applied transfers; however, accessory nerve-musculocutaneous nerve transfer can result in MRC Grade 3 or higher in between 50 and $75 \%$ of the patients. ${ }^{27,32}$ This indicates that the accessory nerve is a useful donor for nerve transfer, at least for elbow flexion. Intrinsic qualities related to the intercostal nerve and accessory nerve donor nerves play a role in restoring functional outcome for the regain of elbow flexion and shoulder function. It seems likely, however, that intrinsic physiological aspects of movement may account for the remarkable difference in levels of recovery between elbow flexion and shoulder function, not in the least because elbow flexion is a relatively simple movement compared with active shoulder function, considering that the various shoulder muscles require coordinated contraction to realize the diversity of movement directions.

\section{Strategy for Nerve Repair}

The question arises whether the outcome after shoulder function reanimation in patients with proximal C-5 and C-6 lesions and extensive loss of nerve tissue can be improved by changing the basic nerve surgical strategy without jeopordizing biceps muscle recovery. A possible strategy, when more than one graft can be coapted to the C-5 proximal stump and when C-6 is available for the biceps, is to graft $\mathrm{C}-5$ exclusively to the axillary nerve and combine it with accessory nerve-suprascapular nerve transfer. Although we have not performed this yet, in view of the findings of the present study it is questionable whether this type of change would indeed improve outcome. Whether grafting from the best available proximal stump to axillary nerve and/or suprascapular nerve instead of using it for the biceps results in better shoulder function remains to be established.

Good shoulder function outcome is especially important for positioning a functionally intact hand. Recently, two types of intraplexal nerve transfers for patients with C-5/C-6 lesions have been reported to be successful in combination with accessory nerve-suprascapular nerve transfer-namely, that of the nerve to the long head of the triceps to the axillary nerve,$^{15}$ and the medial pectoral nerve to the axillary nerve. ${ }^{29}$ The results of extraplexal-intraplexal transfers such as phrenic nerve to suprascapular nerve, ${ }^{7,22,34,38}$ phrenic nerve to axillary nerve, ${ }^{7}$ and intercostal nerves to axillary nerve,$^{22}$ have been claimed to be rather good; however, the use of the phrenic nerve as a donor has not been widely implemented until now.

\section{CONCLUSIONS}

Active glenohumeral shoulder function recovery after nerve repair of the suprascapular nerve in patients with proximal C-5 and C-6 lesions and extensive nerve tissue loss is poor. Grafting from C-5 to the suprascapular nerve with, if the occasion arises, grafting to the axillary nerve is of limited value in these patients. At present we recommend only the accessory nerve-suprascapular nerve transfer in patients with good hand function, when direct coaptation is possible and only when grafting to the posterior division of the superior trunk can be realized. The profession and hobbies of the patient, however, should also be considered because limited shoulder function can sometimes be of value.

\section{References}

1. Allieu Y, Cenac P: Neurotization via the spinal accessory nerve in complete paralysis due to multiple avulsion injuries of the brachial plexus. Clin Orthop 237:67-74, 1988

2. Alnot JY: Traumatic brachial plexus palsy in the adult. Retroand infraclavicular lesions. Clin Orthop 237:9-16, 1988

3. Alnot JY, Bonnard C, Allieu Y, et al: Les paralysies traumatiques C5-C6 et C5-C6-C7 par lesions supraclaviculaires, in Alnot JY, Narakas A (eds): Les Paralysies du Plexus Brachial, ed 2. Paris: Expansion Scientifique Francaise, 1995, pp 188-195

4. Birch R, Bonney G, Wynn Parry CB: Surgical Disorders of the Peripheral Nerves. London: Churchill Livingstone, 1998, p 539

5. Bonnard C, Narakas A: Neurotisation par le nerf spinal dans les lésions du plexus brachial, in Alnot JY, Narakas A (eds): Les 
Paralysies du Plexus Brachial, ed 2. Paris: Expansion Scientifique Francaise, 1995, pp 165-175

6. Bonnel F, Allieu Y, Sugata Y, et al: Anatomico-surgical bases of neurotization for root-avulsion of the brachial plexus. Anat Clin 1:291-296, 1979

7. Chuang DC, Lee GW, Hashem F, et al: Restoration of shoulder abduction by nerve transfer in avulsed brachial plexus injury: evaluation of 99 patients with various nerve transfers. Plast Reconstr Surg 96:122-128, 1995

8. Dailiana ZH, Mehdian H, Gilbert A: Surgical anatomy of spinal accessory nerve: is trapezius functional deficit inevitable after division of the nerve? J Hand Surg Br 26:137-141, 2001

9. Dubuisson AS, Kline DG: Brachial plexus injury: a survey of 100 consecutive cases from a single service. Neurosurgery 51:673-683, 2002

10. El-Gammal TA, Fathi NA: Outcomes of surgical treatment of brachial plexus injuries using nerve grafting and nerve transfers. J Reconstr Microsurg 18:7-15, 2002

11. Guazzelli Filho J, Furlani J, De Freitas V: Electromyographic study of the trapezius muscle in free movements of the arm. Electromyogr Clin Neurophysiol 31:93-98, 1991

12. Kapandji IA: Physiologie Articulaire: Schémas Commentés de Mécanique Humaine, ed 5. Paris: Maloine, 19805

13. Kim DH, Cho YJ, Tiel RL, et al: Outcomes of surgery in 1019 brachial plexus lesions treated at Louisiana State University Health Sciences Center. J Neurosurg 98:1005-1016, 2003

14. Kline DG, Hudson AR: Nerve Injuries: Operative Results for Major Nerve Injuries, Entrapments, and Tumors. Philadelphia: WB Saunders, 1995, p 611

15. Leechavengvongs $\mathrm{S}$, Witoonchart $\mathrm{K}$, Uerpairojkit $\mathrm{C}$, et al: Nerve transfer to deltoid muscle using the nerve to the long head of the triceps, part II: a report of 7 cases. J Hand Surg Am 28:633-638, 2003

16. Malessy MJA, Bakker D, Dekker AJ, et al: Functional magnetic resonance imaging and control over the biceps muscle after intercostal-musculocutaneous nerve transfer. J Neurosurg 98: 261-268, 2003

17. Malessy MJA, Hoffmann CF, Thomeer RTWM: Initial report on the limited value of hypoglossal nerve transfer to treat brachial plexus root avulsions. J Neurosurg 91:601-604, 1999

18. Malessy MJA, Thomeer RTWM: Evaluation of intercostal to musculocutaneous nerve transfer in reconstructive brachial plexus surgery. J Neurosurg 88:266-271, 1998

19. Malessy MJA, van der Kamp W, Thomeer RTWM, et al: Cortical excitability of the biceps muscle after intercostal-tomusculocutaneous nerve transfer. Neurosurgery 42:787-795, 1998

20. Malessy MJA, van Duinen SG, Feirabend HK, et al: Correlation between histopathological findings in C-5 and C-6 nerve stumps and motor recovery following nerve grafting for repair of brachial plexus injury. J Neurosurg 91:636-644, 1999

21. Merrell GA, Barrie KA, Katz DL, et al: Results of nerve transfer techniques for restoration of shoulder and elbow function in the context of a meta-analysis of the English literature. J Hand Surg Am 26:303-314, 2001

22. Nagano A, Yamamoto S, Mikami Y: Intercostal nerve transfer to restore upper extremity functions after brachial plexus injury. Ann Acad Med Singapore 24 (Suppl 4):42-45, 1995

23. Narakas AO: Examen du patient et de la fonction des divers groupes musculaires du membre superieur, in Alnot JY, Narakas A (eds): Les Paralysies du Plexus Brachial, ed 2. Paris: Expansion Scientifique Francaise, 1989, pp 49-64

24. Narakas AO: Brachial plexus injuries, in McCarthy JG, May JW, Littler WJ (eds): Plastic Surgery. Philadelphia: WB Saunders, Vol 3, 1990, pp 4776-4816

25. Oberlin C, Beal D, Leechavengvongs S, et al: Nerve transfer to biceps muscle using a part of ulnar nerve for C5-C6 avulsion of the brachial plexus: anatomical study and report of four cases. J Hand Surg Am 19:232-237, 1994

26. Radin EL: Biomechanics and functional anatomy, in Post $\mathrm{M}$ (ed): The Shoulder: Surgical and Nonsurgical Management, ed 2. Philadelphia: Lea \& Febiger, 1988, pp 54-60

27. Samardzic M, Grujicic D, Antunovic V: Nerve transfer in brachial plexus traction injuries. J Neurosurg 76:191-197, 1992

28. Samardzic M, Grujicic D, Rasulic L, et al: Restoration of upper arm function in traction injuries to the brachial plexus. Acta Neurochir 144:327-335, 2002

29. Samardzic M, Grujicic D, Rasulic L, et al: Transfer of the medial pectoral nerve: myth or reality? Neurosurgery 50: 1277-1282, 2002

30. Schai PA, Hintermann B, Koris MJ: Preoperative arthroscopic assessment of fractures about the shoulder. Arthroscopy 15: 827-835, 1999

31. Seddon HJ: Peripheral Nerve Injuries. Medical Research Council Special Report Series 282. London: HMSO, 1954

32. Songcharoen P: Brachial plexus injury in Thailand: a report of 520 cases. Microsurgery 16:35-39, 1995

33. Sunderland S: Nerve Injuries and Their Repair: A Critical Appraisal. Edinburgh: Churchill Livingstone, 1991, p 538

34. Sungpet A, Suphachatwong C, Kawinwonggowith V: Restoration of shoulder abduction in brachial plexus injury with phrenic nerve transfer. Aust N Z J Surg 70:783-785, 2000

35. Terzis JK, Vekris MD, Soucacos PN: Outcomes of brachial plexus reconstruction in 204 patients with devastating paralysis. Plast Reconstr Surg 104:1221-1240, 1999

36. Thomeer RTWM, Malessy MJA: Surgical repair of brachial plexus injury. Clin Neurol Neurosurg 95 (Suppl):S65-S72, 1993

37. Vacher C, Dauge MC, Bhatia A, et al: Is the hypoglossal nerve a reliable donor nerve for transfer in brachial plexus injuries? Plast Reconstr Surg 112:708-710, 2003

38. Waikakul S, Orapin S, Vanadurongwan V: Clinical results of contralateral $\mathrm{C} 7$ root neurotization to the median nerve in brachial plexus injuries with total root avulsions. J Hand Surg Br 24:556-560, 1999

Manuscript received March 22, 2004.

Accepted in final form April 26, 2004.

Address reprint requests to: Martijn J.A. Malessy, M.D., Ph.D., Department of Neurosurgery, Leiden University, Medical Center, P.O. Box 9600, 2300 RC Leiden, The Netherlands. email: M.J.A.Malessy@lumc.nl. 